\title{
SYNTHESIS AND CHARACTERIZATION OF BISMERCAPTO (2, 2':6', 2'”-terpyridine) Ru(II)-COMPLEXES STABILIZED GOLD NANOPARTICLES AND THEIR ELECTRO CATALYTIC REDUCTION OF NITRITE
}

\author{
MARGANDAN K $K^{1}$ JEBASTIN SONIA JAS M² \\ ${ }^{1,2}$ Department of Chemistry, IFET College of Engineering, Villupuram-605108, India
}

\begin{abstract}
Inorganic-organic hybrid structures based on metal-complexes particularly, octahedral bis-2,2':6',2''- terpyridine metal complexes provide an advantages of increased symmetry and in the case of ruthenium(III)/ruthenium(II) complexation an entrance to a directed complexation Method. The Ru (II) terpyridine methane thiolate protected gold nanoparticle was synthesized through covalent bonding of Ru terpyridine methane thiolates over gold nanoparticles surfaces. The ligand terpyridine methanethiolate was synthesized successfully in good percentage of yield. The structures were confirmed and characterized by different physical, analytical, spectral data like FTIR, UV, SEM and Cyclic voltammetry. All the data are shown the expected results.
\end{abstract}

Keywords: Ru(II) terpyridine, Au nanopaprticles, thiolates, electro catalytic reduction of nitrite

\section{INTRODUCTION}

2, 2'-bipyridine (bpy) has been announced to be "the most used ligand in coordination chemistry" ', 2, 2':6', 2'”-terpyridine (tpy) also has a rich chemistry. The coordination chemistry of the substituted terdentate ligand has attracted many chemists. 2, 2':6', 2' '-terpyridine has been reacted with very many metals to prepare complexes. The kinetics and mechanism of formation of metal complexes and their stability have also been studied ${ }^{2-6}$. 2,2'-bipyridyl has take part in an important role in building many mixed-ligand complexes for their desired predictable co-ordination behavior and their photophysical and electrochemical properties ${ }^{7-9}$. The 2,2'-bipyridyl and ligands derived from it also extensively used in different areas, such as supramolecular assemblies, molecular scaffolding, electrochemistry catalysis, biochemistry, and biochemistry, ring-opening metathesis polymerization ${ }^{10-15}$, biologically photoredox reactions ${ }^{16}$, synthetic, medicinal chemistry, biotechnology ${ }^{17}$ and solar cell ${ }^{18}$. Synthesis of TiO $-\mathrm{Al}_{2} \mathrm{O}-\mathrm{SiO}_{2}$ nanopowder composite, as well as composite coating on soda lime glass and Si (100) by sol-gel method is reported ${ }^{19}$. We demonstrate here the application of this approach to the formation of stable inorganic nanocomposties featuring systematic control of interparticle spacing. Metal-mediated nanoparticle assembly was studied using mixed monolayer protected gold clusters (MMPCs). In these nanoparticles, the distance of the terpyridine functionality to the metal core was systematically varied by altering the chain lengths of the terpy ligand and the supporting monolayers. The comparison of interparticle spacing as a function of monolayer thickness required uniform cluster core size for MMPCs. The control of core size was achieved by using the pentane thiol stabilized monolayer protected cluster (MPC) as the nanoparticles source for the fabrication of all MMPCs. MPC was prepared following a previously reported protocol.
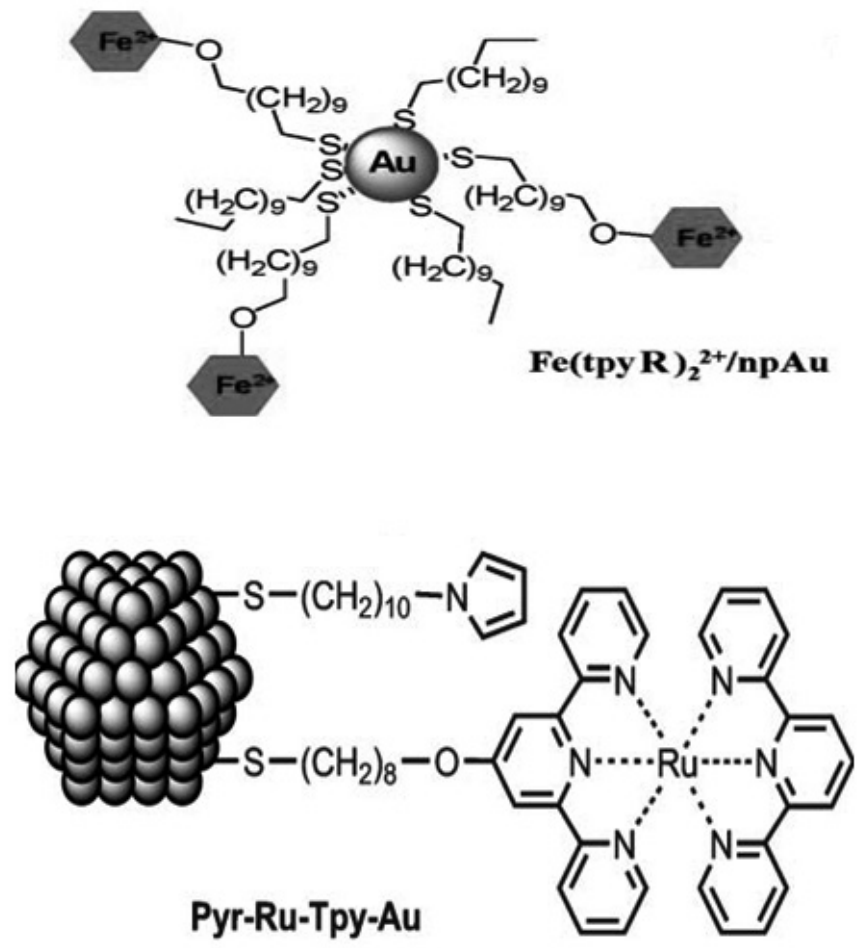

In present investigation, is to synthesized metal terpyridine complex protected with $\mathrm{Au}$ nanoparticle. The characterization of that nanoparticle is also tested.

\section{Experimental Details}

Step 1: 2-(6-pyridin-2-yl)-4-p-tolylpyridin-2yl) pyridine

2-acetylpyridine ( $4 \mathrm{ml}, 35.6 \mathrm{mmol}$ ) was added to a suspension of crushed $\mathrm{NaOH}(1.44 \mathrm{~g}, 0.036 \mathrm{mmol})$ in PEG400 $(50 \mathrm{ml})$, and stirred at ice cold temperature for 10 minutes. 4-methylbezaldehydide $(2.2 \mathrm{ml}, 18 \mathrm{mmol})$ was 
then added by syringe and the suspension left standing at ice cold temperature for $2 \mathrm{hrs}$. Stirred with magnetic stirrer, the solution became red and high viscous. After $2 \mathrm{hrs}$, $\mathrm{NH}_{4} \mathrm{OAc}\left(8 \mathrm{~g}\right.$, excess) was added and the suspension heated at $100^{\circ} \mathrm{C}$ for $2 \mathrm{hrs}$. During this time, the colour of the mixture changed from red to brown, and accompanied by formation of a fine brown precipitate of the product ${ }^{20-30}$. Water (50 ml) was added and the pasty precipitate of $2-(6-p y r i d i n-2-y l)-4-p-$ tolylpyridin-2yl) pyridine isolated, washed with water $(50 \mathrm{ml})$ and cold $\mathrm{EtOH}(50 \mathrm{ml})$. Light yellow massive powder yield: $1.902 \mathrm{~g}$.

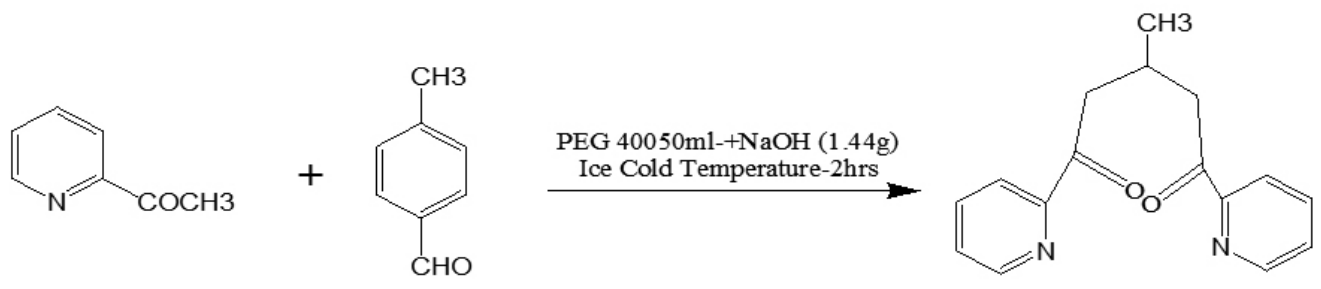

1-(pyridin-2-yl)ethanone

$$
\text { 4-methylbenzaldehyde }
$$

3-methyl-1,5-di(pyridin-2-yl)pentane-1,5-dione

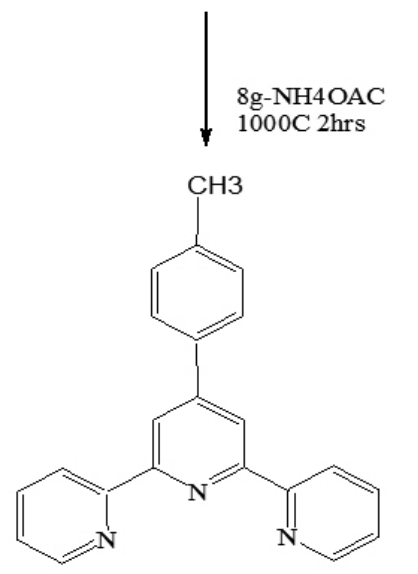

2-(6-(pyridin-2-yl)-4-p-tolylpyridin-2-yl)pyridine

Step: 2

4'-(4-Bromomethylphenyl)-[2,2':6',2']terpyridine.

A mixture of $4^{\prime}$-(methyl phenyl)-2,2':6',2'-terpyridine (1.6g, 4.8mmol), $N$-bromsuccinimide (NBS, $1.22 \mathrm{~g}, 7.4 \mathrm{mmol}$ ), and R, $\mathrm{R}^{\prime}$-azoisobutyroniltrile (AIBN, $0.08 \mathrm{~g}, 0.48 \mathrm{mmol})$ in dry $\mathrm{CCl}_{4}(60 \mathrm{ml})$ was refluxed for $2 \mathrm{hrs}$. The warm reaction mixture was filtered to remove the succinimide, and the solvent was evaporated by Rota vapor. The crude product was pale-yellow solid yield: $1.1611 \mathrm{~g} .{ }^{31}$

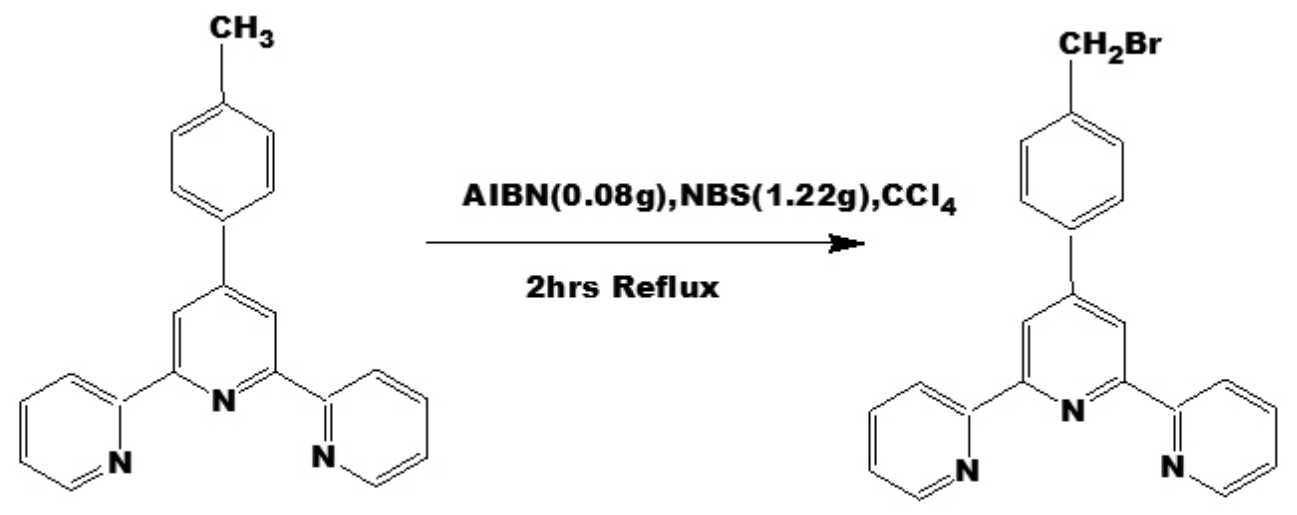

\section{2-(6-(pyridin-2-yl)-4-p-tolylpyridin-2-yl)pyridine}

Step: 3

4'-(4-mercaptomethylphenyl)-2, 2':6, 2',-terpyridine

A solution of 4'-(4-bromomethylphenyl)-2, 2':6, 2'"-terpyridine (0.5212 g, $1.24 \mathrm{mmol})$ and $0.048 \mathrm{~g}(1.34 \mathrm{mmol})$ of thiourea in $130 \mathrm{ml}$ of ethanol-acetone mixture resolvents $(1: 1, \mathrm{v} / \mathrm{v})$ was heated at reflux for $22.5 \mathrm{~h}$. After cooling, the precipitate was filtered, washed with acetone, and dried to give $0.481 \mathrm{~g}(89 \%)$. A mixture of $(0.481 \mathrm{~g}, 1.21 \mathrm{mmol})$ and $\mathrm{NaOH}(0.42 \mathrm{~g}, 1.1 \mathrm{mmol})$ in $40 \mathrm{ml}$ of water was heated at $70^{\circ} \mathrm{C}$ for $4.5 \mathrm{~h}$. After cooling, the precipitate was filtered and washed with water, and then dried under vacuum at room temperature overnight to give 4'-(4-mercaptomethylphenyl)-2, 2':6, 2'”-terpyridine (1.324 g). ${ }^{32,33}$ 
Step: 4. Synthesis of terpyridine Ruthenium (III) Complexes.

2, 2':6'2'-terpyridine (mterpy-SH) $(0.20 \mathrm{~g}, 1.23 \mathrm{mmol})$ ) was added to $\mathrm{RuCl}_{3} \cdot 3 \mathrm{H}_{2} \mathrm{O}(100 \mathrm{mg}, 1.23 \mathrm{mmol})$ in ethanol and refluxed for 8 hrs under an inert atmosphere. The mixture was cooled and the dark brown precipitate was collected by filtration, washed thoroughly with methanol, water and diethyl ether and dried under vacuum. Yield: $0.20 \mathrm{~g}$.<smiles>BrCc1ccc(-c2cc(-c3ccccn3)nc(-c3ccccn3)c2)cc1</smiles>

2-(4-(4-(bromomethyl)phenyl)-6-(pyrid in-2-yl)pyrid in2-yl)pyrid ine
1.Thio urea, 22.5hr

2. $\mathrm{NaOH}, 70^{\circ} \mathrm{C} .4 .5 \mathrm{hr}$<smiles>SCc1ccc(-c2cc(-c3ccccn3)nc(-c3ccccn3)c2)cc1</smiles>

s-4-(2,6-di(pyridin-2-yl)pyr id in-4-yl)benzyl ethanethioate

Step: 5. Synthesis of ruthenium (II) complexes

terpy $(0.131 \mathrm{~g}, 0.812 \mathrm{mmol})$ was added to $[\mathrm{Ru}(\mathrm{mterpy}-\mathrm{SH})] \mathrm{Cl}_{3}(0.20 \mathrm{~g}, 0.813 \mathrm{mmol})$ in methanol along with $N$-ethylmorpholine (5 drops). The mixture was refluxed for $6 \mathrm{hrs}$ and an inert atmosphere. The resulting deep red solution was filtered and a three-fold excess of methanolic ammoniumhexafluorophosphate was added to the filtrate. The resulting red precipitate was filtered off and recrystallized from acetone-acetonitrile solution and dried under vacuum. Yield: $0.750 \mathrm{~g}$<smiles>SCc1ccc(-c2cc(-c3ccccn3)nc(-c3ccccn3)c2)cc1</smiles>

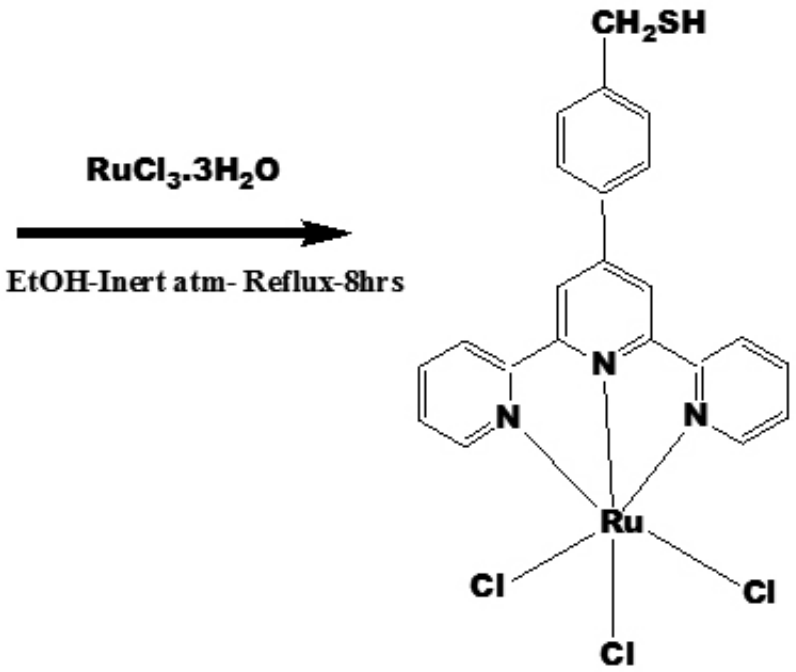

Step: 6. Synthesis of Ru-Terpyridinethiolates functionalized AuNPs nanoparticles.

The ligand-exchange reaction of Ru-Terpy-Au with a Citrate capped AuNPs was carried out as follows. A mixture of $\left[\mathrm{Ru}-(\mathrm{TerpySH})_{2}\right]^{2+}(50 \mathrm{mg})$ and AuNPs $(5 \mathrm{ml})$ were added in $\mathrm{MeCN}(10 \mathrm{~mL})$ was stirred at room temperature for $48 \mathrm{hrs}$. To the mixture was added $\mathrm{EtOH}(200 \mathrm{~mL})$ and then the resulting precipitate was collected by filtration and washed several times with $\mathrm{EtOH}$. The nanoparticles were dissolved in MeCN to purify and precipitated with EtOH, and then the particles were isolated by filtration. 

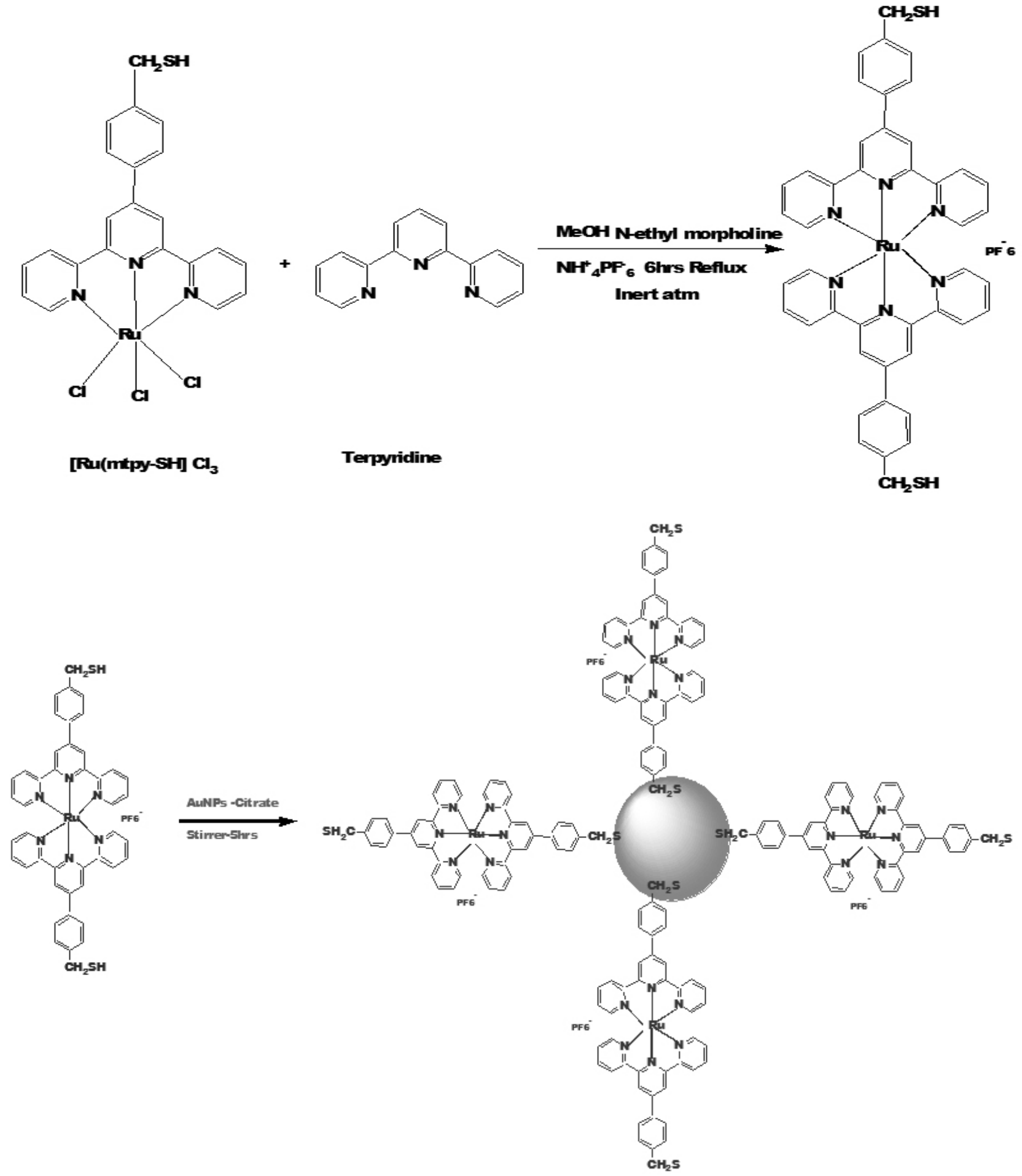

\section{RESULT AND DISCUSSION}

3.1 UV-Visible Spectrum

The grafting of terpy SH is confirmed by the presence of a peak at $276 \mathrm{~nm}$, attributed to $\pi-\pi^{*}$ transitions from the aromatic groups. The terpyridine groups of terpy SH molecules were exposed and provide sites for the coordination of ruthenium ions. Addition of ruthenium ions to the terpy SH functionalized
$\mathrm{Au}-\mathrm{NPs}$ led to a further decrease of the intensity. Moreover, the presence of a shoulder at $520 \mathrm{~nm}$, attributed to the metal to ligand charge transfer (MLCT) of $\left[\mathrm{Ru} \text { (terpySH) }{ }_{2}\right]^{2+}$, confirmed the in situ formation of the bis-terpyridine ruthenium complex. This feature is already observed after complexation of prefunctionalized spherical gold nanoparticles ${ }^{24}$. Functionalization of Au-NRPs by preformed $\left[\mathrm{Ru}(\text { terpySH})_{2}\right]$ the spectra were recorded upon excitation at 280 $\mathrm{nm}$. The result is shown in fig. $4 \mathrm{a}$ and $4 \mathrm{~b}$. 

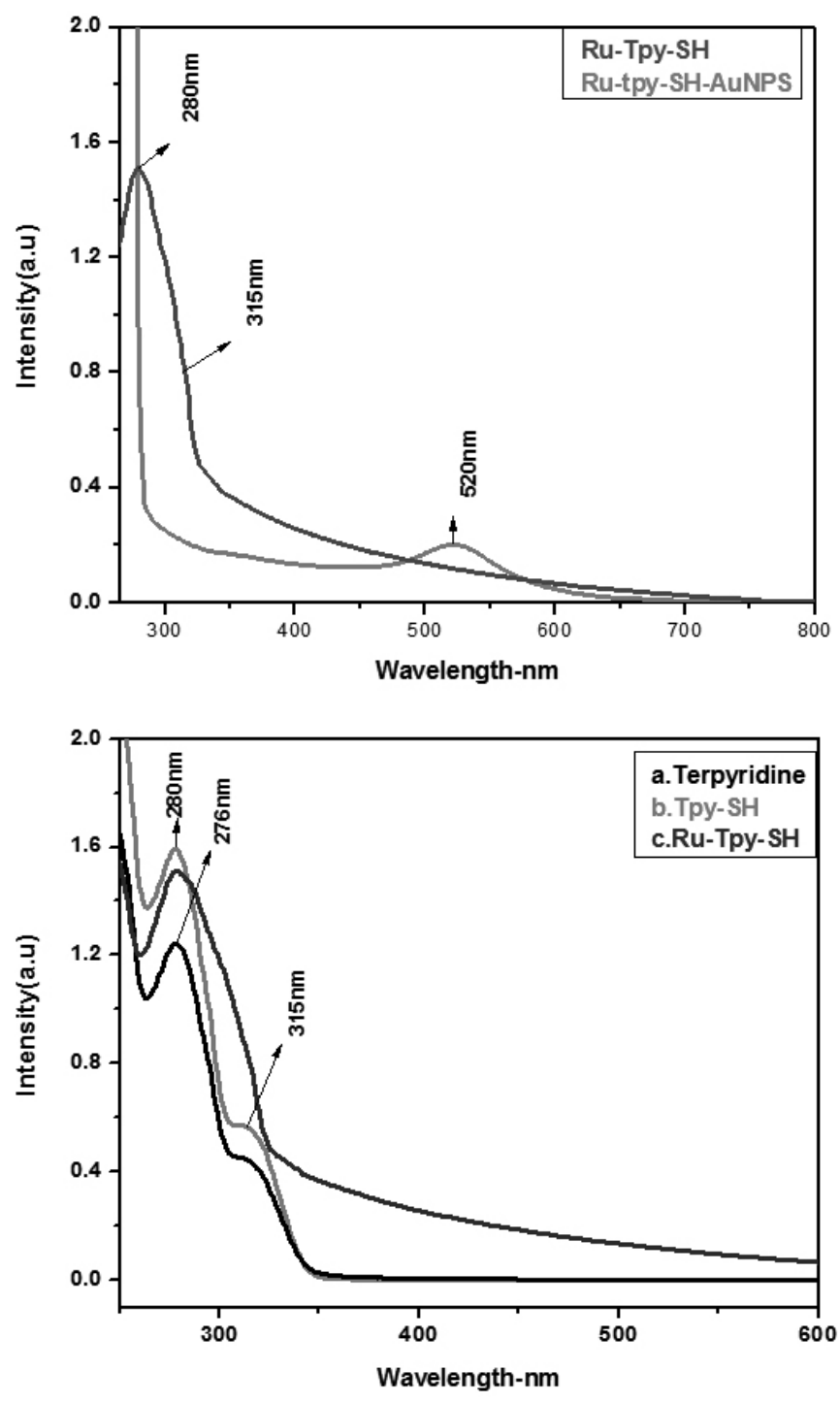

Fig. $4 a$ and $4 b$.

\section{2 FT-IR Spectrum.}

FT-IR spectrum showed characteristic absorption bands at 3052, 1602 and $1466 \mathrm{~cm}^{-1}$ (aromatic); 1584, $1566 \mathrm{~cm}-1(\mathrm{C}=\mathrm{C}$ and $\mathrm{C}=\mathrm{N}$ stretching vibration of pyridine); $824,792 \mathrm{~cm}^{-1}$ (C-H deformation vibration of pyridine); $740 \mathrm{~cm}^{-1}$. terpyridine ligands and their complexation deformation of pyridine; 2926, $2854 \mathrm{~cm}^{-1}$ (C-H stretching of aliphatic) and $962 \mathrm{~cm}^{-1}$. FT-IR-Spectrum of [Ru $\left(\text { terpy-SH) }{ }_{2}\right]^{2+},\left[\mathrm{Ru}\left(\text { terpy-SAuNPs) }{ }_{2}\right]^{2+}\right.$ are shown below.

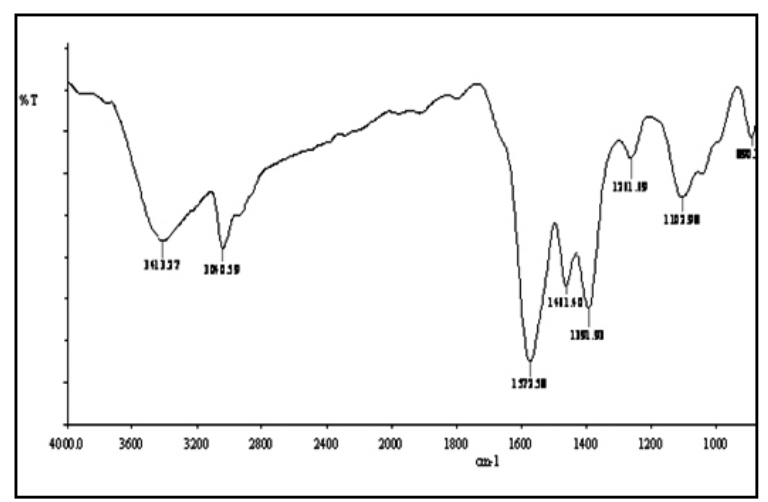

The result shows in fig. $5 \mathrm{a}, 5 \mathrm{~b}, 5 \mathrm{c}$.

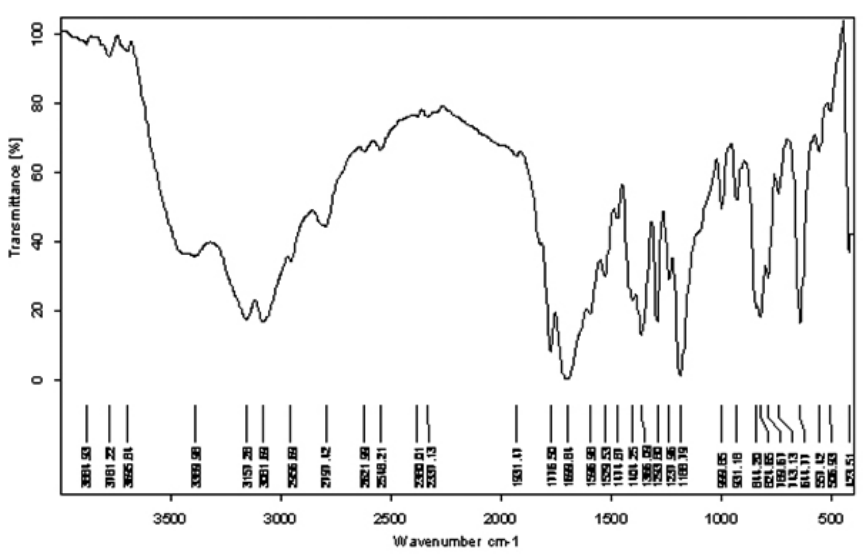

Fig. 5a Terpyridine.

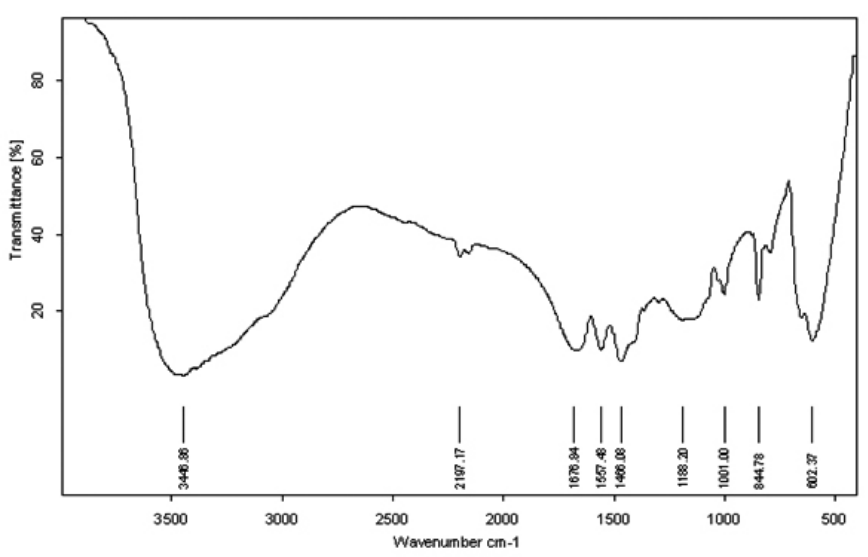

Fig. 5b (Bromomethylphenyl)terpyridine.

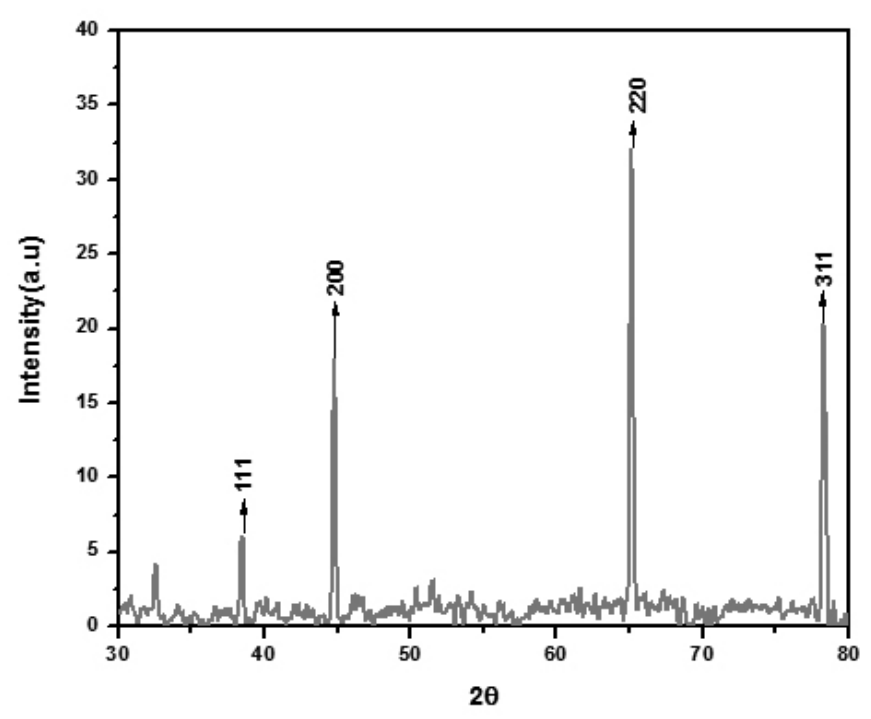

Fig. 5c Ru-Terpyridinethiolates.

3.3. X-ray diffraction of Ru-Terpy-SAuNPs.

XRD spectrum measurements confirm that the crystal structures of the nanoparticles are face-center-cubic (fcc) (Joint Committee for Powder Diffraction Standards (JCPDS). Moreover, XRD pattern of the gold sample with the $\mathrm{Ru}-\mathrm{Terpy}-\mathrm{S}-\mathrm{Au}$ nanoparticles synthesized indicating that crystalstructure of the nanoparticles was FCC (JCPDS 4-0783). 
Fig. 7: X-ray diffraction of Ru-Terpy-SAuNPs.

\subsection{SCANNING ELECTRON MICROSCOPE.}

This result indicates that the Ru-(terpy) ${ }^{2+}$ complexes are present. Field emission scanning electron microscopy (FESEM) indicates a rather smooth and homogeneous surface structure with few aggregates distributed statistically over the substrate (Fig. 8a, 8b) shows a FESEM micrograph of the same diluted sample with isolated $\mathrm{Au}$ nanoparticles of spherical shape and of an average apparent size of about $100 \mathrm{~nm}$. The SEM pictures evidence the existence of nanoparticles with EDAX. The results shows in fig. 9.
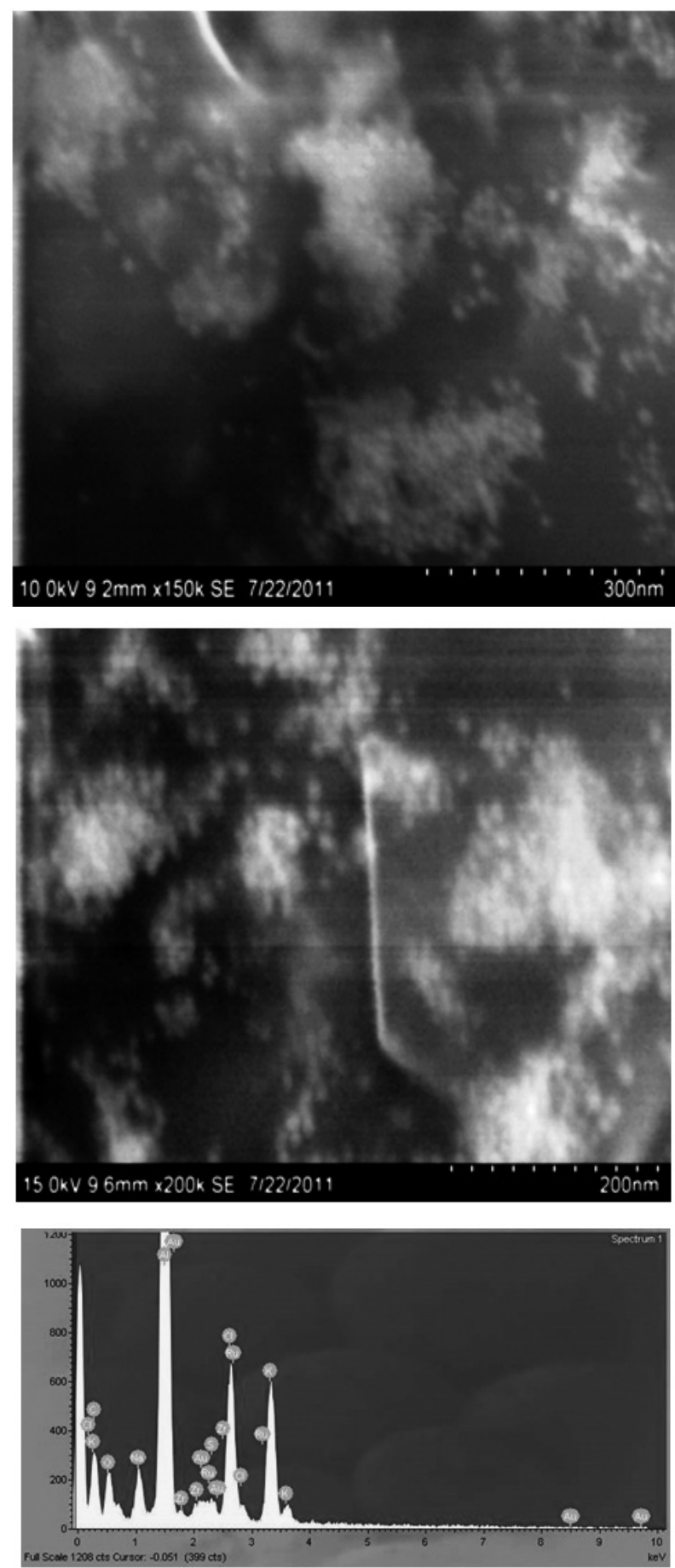

Fig. 8a, 8b and 9 SEM- Ruthenium- Terpyridine-S-AuNPs-Complexes and EDAX. 3.5
AuNps

3.5 Electrochemical Studies- Terpyridine Complexes-Ru-Terpy-

The complex is electrochemically active and exhibits a reversible ( 83 $\mathrm{mV}$ ) ruthenium (II/III) process at $+0.9 \mathrm{~V}$ in $\mathrm{MeCN}$ solution of interest for potential applications of this type of complex in electrochemical devices, is the observation of a second quasi-reversible process at $+1.08 \mathrm{~V}$ assigned to the oxidation of the thioether sulfur. This second process is absent in the model complex $\left[\mathrm{Ru}(\text { terpySH})_{2}\right][\mathrm{PF} 6]_{2}$ (terpy $=2,2^{\prime}: 6^{\prime}, 2^{\prime \prime}$ '-terpyridine) and is characteristic of the thioether-functionalised compounds.

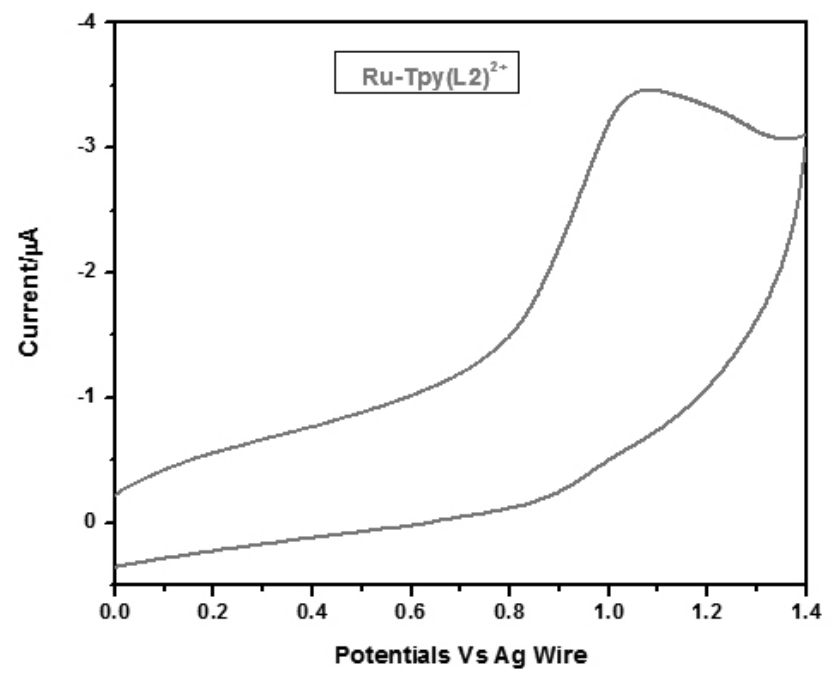

Fig. 10: Terpyridine complexes -Ru-Terpy-AuNPs.

\subsection{Electro Modification Of Complexes Studies Of Ru-Terpy-Au.}

The electro activity of Ru-Terpy-Au was performed by cyclic voltammetry (CV). The first scan of the $\mathrm{CV}$ of $\mathrm{Ru}-\mathrm{Terpy}-\mathrm{Au}$ in $0.1 \mathrm{M}$ TBAP-MeCN at a GC electrode exhibited a single irreversible oxidation wave at Ep $=+1.16$ $\mathrm{V}$ (vs. $\mathrm{Ag} / 0.1 \mathrm{M} \mathrm{AgNO}_{3}$ ) which seems to overlap the oxidation peaks of the ruthenium(II)/(III) couple. Repeat scans showed an increase in the redox-peak currents. After fifty scans, the electrode was rinsed copiously with solvent and dipped into fresh $0.1 \mathrm{M}$ TBAP-MeCN solutions. The $\mathrm{CV}$ of the $\mathrm{Ru}-\mathrm{Terpy}-$ Au modified GC electrode showed two irreversible peaks due to terpyridine at 21.58 and $21.91 \mathrm{~V}$ and one reversible redox peak due to the $\mathrm{Ru}(\mathrm{II}) /(\mathrm{III})$ couple at $+0.95 \mathrm{~V}(\Delta \mathrm{Ep}=114 \mathrm{mV})$. Thus metal nanoparticles bearing a $\mathrm{Ru}$-terpyridine complex are readily immobilized on metal electrode surfaces.

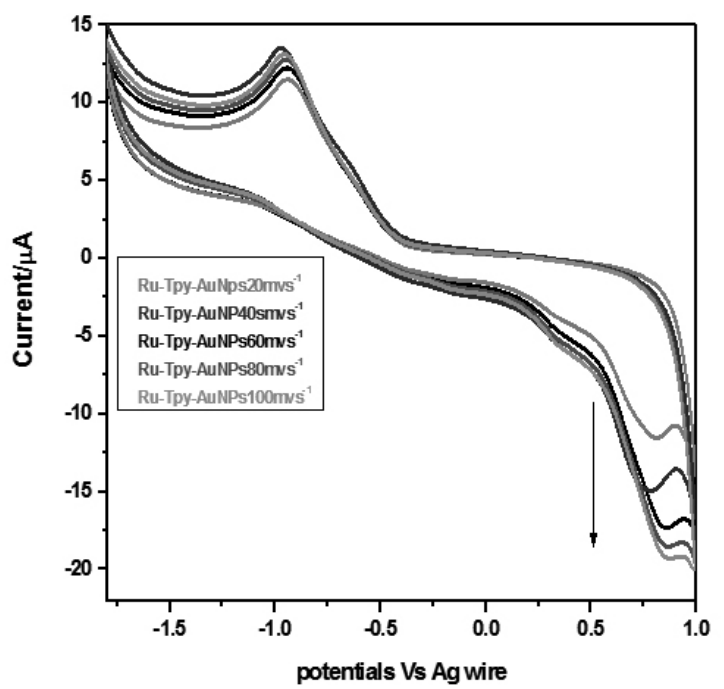

Fig. 11: Electro modification of complexes studies of Ru-Terpy-Au. 
3. 7 Electrocatalysis Of Nitrite Reduction By Using Ru-(Terpys) ${ }^{2+} \mathrm{Au}$ Nps/GC Modified

At a bare GC and at the modified GC in $0.1 \mathrm{M}$ phosphate buffer solution $\mathrm{pH}$ 7. This fig. 12 shows the GC bare electrode no cathodic reduction current, and modified GC electrode reduction of nitrite cathodic negative potential is high compare than GC electorde. Increasing the cathodic peak current increases with different scan rate by using $\left[\mathrm{Ru}\right.$ (terpyS-AuNPs) ${ }_{2}^{2+} / \mathrm{GC}$ modified electrode. The reduction of Nitrite $\mathrm{Ru}^{\text {(II) }}\left[\left(\text { terpyS-AuNPs) }{ }_{2}\right]^{2+} / \mathrm{GC}\right.$ modified electrode at reduction potential range $-0.68 \mathrm{~V}$ compare than $\mathrm{GC}$ electrode reduction potentials of nitrite fig. 13 .
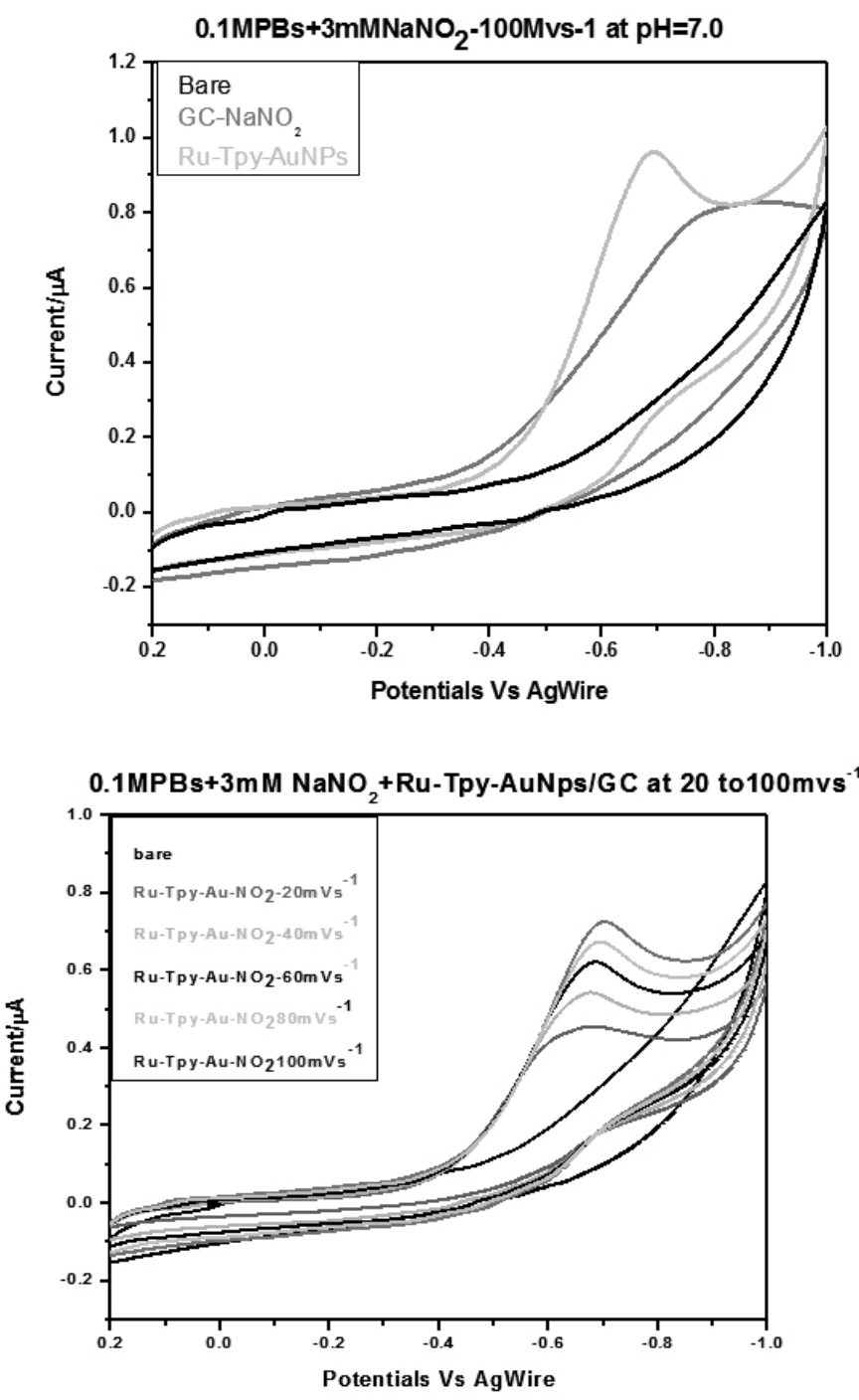

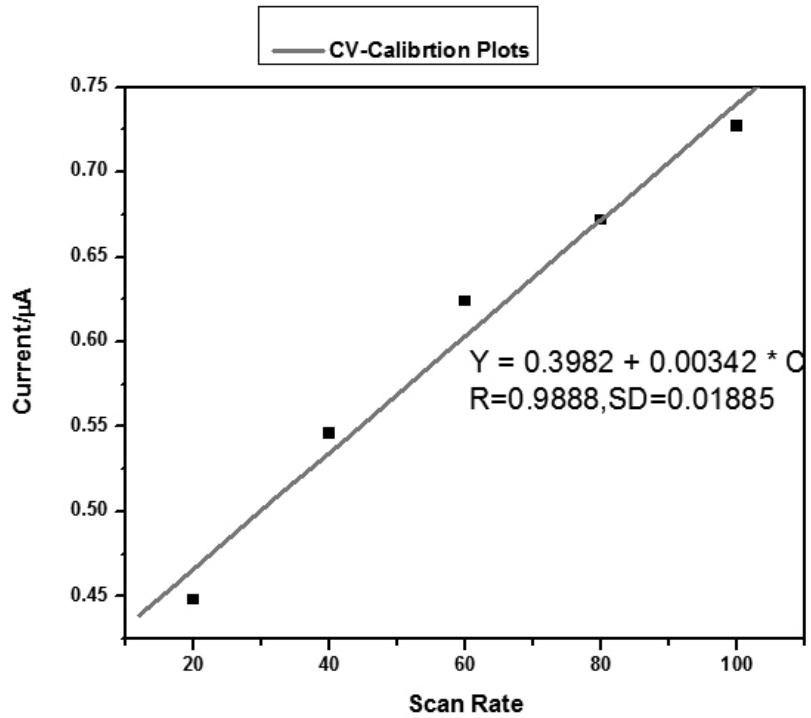

Fig. 12: Electrocatalysis of nitite reduction by using Ru- (TerpyS) ${ }^{2+} \mathrm{AuNps} / \mathrm{GC}$ modifie.

3.8 Electrocatalytic detection of $\mathrm{NaNO}_{2}$ by using GC/Ru-TerpyAuNPs electrode.

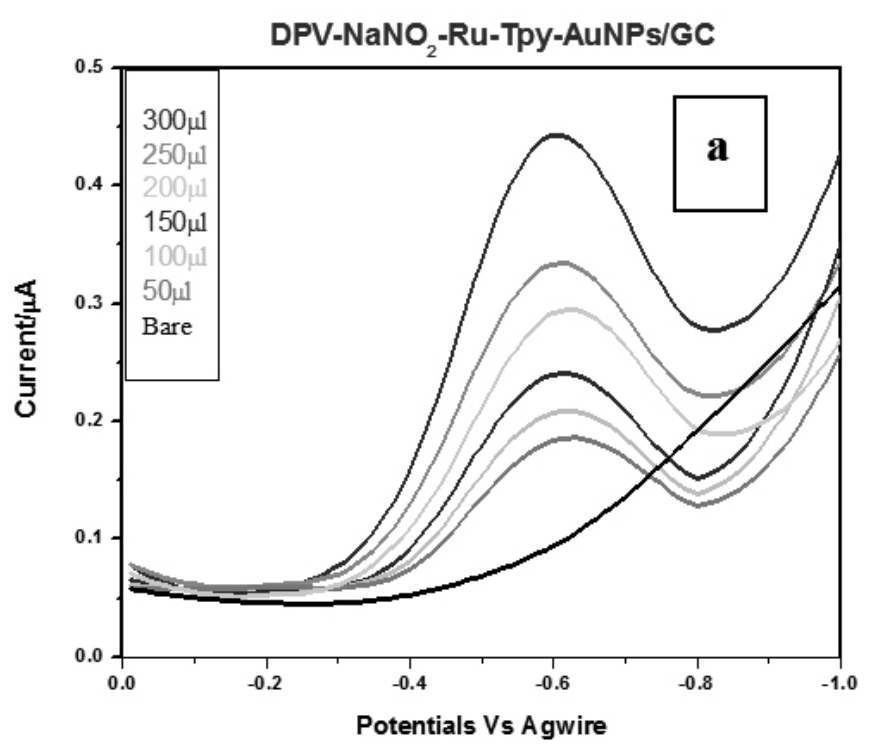



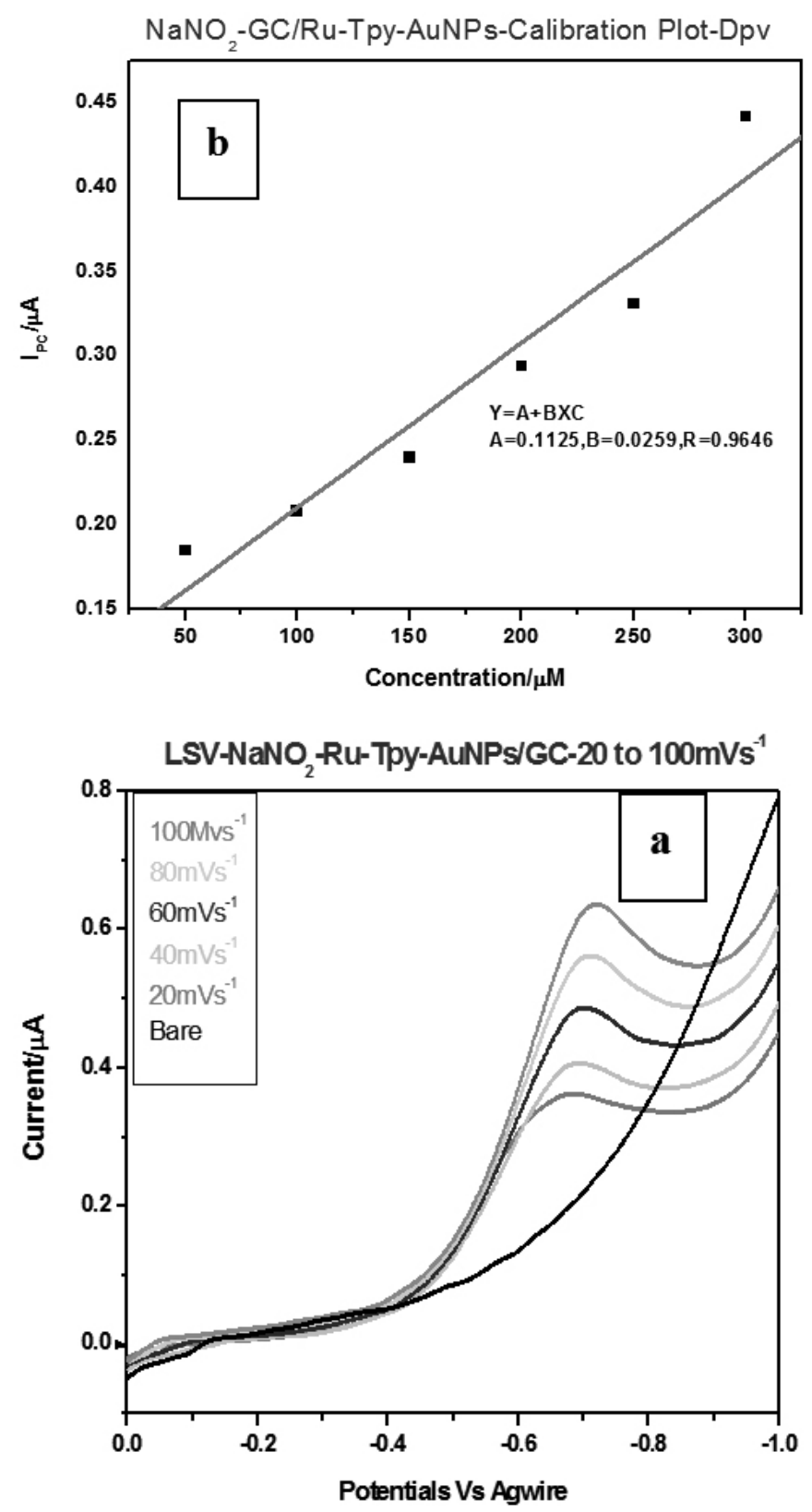

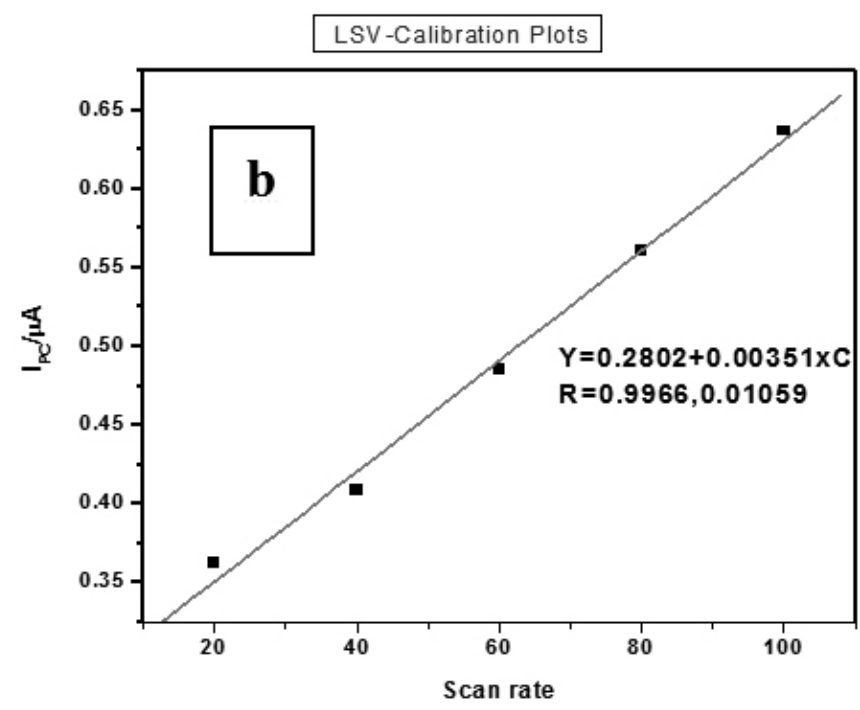

Fig. 13: Electrocatalytic detection of $\mathrm{NaNO}_{2}$ by using $\mathrm{GC} / \mathrm{Ru}-\mathrm{Terpy}-$ AuNPs electrode.

\section{CONCULSION}

The $\mathrm{Ru}$ (II) terpyridine methane thiolate protected gold nanoparticle was synthesized through covalent bonding of $\mathrm{Ru}$ terpyridine methane thiolates over gold nanoparticles surfaces. The ligand terpyridine methanethiolate was synthesized successfully in good percentage of yield. The structures were confirmed and characterized by different physical, analytical, spectral data from, ${ }^{1} \mathrm{H}$ NMR, FTIR, UV, SEM and Cyclic voltammetry. All the data are showing the expected results. The complexes [Ru (terpy-S-AuNPs) $\left.{ }_{2}\right]^{2+}$ modified on GC electrodes at potentials negative of the nitrite reduction peak. The electrochemical response of Ru (terpy-S-AuNPs) $\left.{ }_{2}^{2+}\right]^{2+}$ modified GC electrodes in aqueous solution was more robust than in acetonitrile solution, and the response of the nitrite reduction process was shown to be $\mathrm{pH}$ dependent in solutions out of the range of $\mathrm{pH} 7$. Therefore $\left.[\mathrm{Ru} \text { (terpyS-AuNPs}]_{2}\right]^{2+}$ complex modified GC electrodes were found to catalyze the reduction of nitrite in $\mathrm{pH}-7$ phosphate buffer solution.

\section{REFERENCES}

[1]. Kaes, C.; Katz, A,; Hosseini, M. W.; Chem. Rev. 2000, 100, 3553-3590 [2]. Burstall, F. H.; J. Chem. Soc., 1938, 1662-1672

[3]. Huynh, M. H. V.; El-Samanody, E. S.; Demadis, K.; White, P. S.; Meyer, T. J.; Inorg.Chem. 2000, 39, 3075-3085

[4]. Huynh, M. H. V.; White, P. S.; Meyer, T. J.; Inorg. Chem. 2000, 39, $2825-2830$

[5]. Sanna, G.; Pilo, M. I.; Minghetti, G.; Cinellu, M. A.; Spano, N.; Seeber, R.; Inorg. Chim. Acta 2000, 310, 34-40

[6]. Priimov, G. L.; Moore, P.; Martiim, P. K.; Butalanyi, P. K.; Alcock, N. W.; J. Chem.Soc., Dalton Trans. 2000, 445.

[7] Siebert, R., Winter, A., Dietzek, B., Schubert, U.S. and Popp, J. (2010) MacromolecularRapid Communications, 31,883-888.

[8] Siebert, R., Winter, A., Schubert, U.S., Dietzek, B. and Popp, J. (2010) The Journal of Physical Chemistry C, 114, 6841-6848.

[9] Siebert, R., Winter, A., Schubert, U.S., Dietzek, B. and Popp, J. (2011). Physical ChemistryChemical Physics, 13, 1606-1617.

[10] Binnemans, K., Lenaerts, P., Driesen, K. and Görller-Walrand, C. (2004) Journal of Materials Chemistry, 14, 191-195

[11] Larsson, K. and Öhrström, L. (2004) Inorganica Chimica Acta, 357, 657 664.

[12] Steed, J.W. and Atwood, J.L. (2000) Supramolecular Chemistry. Wiley, Chichester.

[13] Chow, C.S. and Bogdan F.M. (1997). Chemical Reviews, 97, 1489-1514

[14] Sammes, P.G. and Yahioglu, G. (1994) Chemical Society Reviews, 23 327-334.

[15] Balzani, V., Juris, A., Venturi, M., Campagna, S. and Serroni, S. (1996) Chemical Reviews, 96, 759-834. 
[16] Daniel, S. and Gnana Raj, G.A. (2013) Journal of Chemical and Pharmaceutical Research,5, 220-227.

[17] Smith, N.A. and Sadler, P.J. (2013) Philosophical Transactions of the Royal Society A, 373, 20120519.

[18] Monat, J.E., Rodriguez, J.H. and McCusker, J.K. (2002) Journal of Physical Chemistry A, 106, 7399-7406.

[19] M. RiazianiI, J. Chil. Chem. Soc., 61, № 2 (2016) 2870-2877

[20] Constable, E. C.; Khan, F. K.; Raithby, P. R.; Marquez, V. E.; Acta Crystallogr., Sect. C 1992, 48, 932-934

[21] Fallahpour, R. A.; Neuburger, M.; Zehnder, M.; New J. Chem. 1999, 23, 53-61

[22] Bejan, E.; Haddou, H. A.; Darlan, J. C.; Balavoine, G. G. A.; Synthesis 1996, 1012-1018

[23] Schmid, G.; Baumle, M.; Geerkens, M.; Heim,I.; Osemann, C.; Sawitowski, T. Chem. Soc. Rev. 1999, 28, 179-185

[24] Liu, J.; Mendoza, S.; Roma'n, E.; Lynn, M. J.; Xu, R.; Kaifer, A.E. J. Am. Chem. Soc. 1999, 121, 4304.

[25] Lehn, J. M.; Supramolecular Chemistry Concepts and PerspectiVes;
VCH: Weinheim, 1995; p 144-160.

[26] Constable, E. C.; Cargill Thompson, A. M.; W. J. Chem Soc. Dalton. Trans. 1994, 1409- 1418

[27] Ca'rdenas, D. J.; Collin, J. P.; Gavin a, P.; Sauvage, J. P.; De Cian, A. Fischer, J.; Armaroli, N.; Flamigni, L.; Vicinelli,V.; Balzani, V. J. Am. Chem. Soc. 1999, 121, 5481.

[28] Christopher B.; Smith, Colin L.; Raston and Alexandre N.; Sobolev Green Chem., 2005, 7, 650-654

[29] Constable, E. C.; Handel, R.; Housecroft, C. E.; Neuberger, M.; Schofield E. R., and. Zehnder, M.; Polyhedron, 2004, 23, 135

[30] Potts, K. T.; Cipullo, M. J.; Ralli P.; and Theodoridis, G.; J. Org.Chem., 1982, 47, 3027

[31] Bo Tang, Fabiao Yu, Ping Li, Lili Tong, Xia Duan, Ting Xie, and Xu Wang J. Am. Chem. Soc. 9 Vol. 131, NO. 8, 2009

[32] Guangchang Zhou and Issifu I. Harruna Macromolecules 2005, 38, 41144123

[33] Shishan Zhang, Gyu Leem, and T. Randall Lee Langmuir 2009, 25, $13855-13860$ 